\title{
Re-examining the benefits of charitable involvement in housing the mentally vulnerable \\ Nicola Glover-Thomas
}

Reader in Law, University of Liverpool, UK

WARREN BARR

Senior Lecturer in Law, University of Liverpool, UK*

\begin{abstract}
Introduction
$\mathrm{T}$ The traditional social perception of charitable endeavour is a positive one. Charities are perceived to be an essential component of social provision ${ }^{1}$ and make a significant contribution to civil society. ${ }^{2}$ They develop "new services ... [plug] gaps in delivery ... and often focus on meeting the needs of the disadvantaged and socially excluded". ${ }^{3}$ Indeed, charities are being embraced as a necessary aspect of a vibrant and effective third sector, which provides "a new third way"4 for public service provision, harnessing "the sector's strengths to challenge and stimulate new ideas, complement ... shared objectives and take forward the development of social policy generally". ${ }^{5}$ This vision of a shared approach to service provision between the public, private and third sector, with central government in an enabling role, is apparent in all spheres of current public service provision. ${ }^{6}$ The focus of this article, however, is not to consider the important ramifications of the third way on the social housing sector. ${ }^{7}$ It is beyond the remit of this paper to conduct a theoretical and
\end{abstract}

* We are grateful for ESRC funding under a one-year funded project, Housing the Mentally Vulnerable: The Role of Charities (Award Ref: RES-000-22-0286). We would also like to thank Jean McHale, Michael Dougan, Fiona Beveridge and Robert Thomas for their helpful comments. The usual disclaimers apply.

1 See HM Treasury, Exploring the Third Sector in Public Service Delivery and Reform: A discussion document (London: TSO, 2005), ch. 1 (hereinafter referred to as Exploring the Third Sector).

2 A distinction should be recognised between the civil and civic society. Chanan suggests that civic society and participation concerns vertical participation relating to governance, e.g. local strategic partnerships, and a civil society concerns horizontal participation which relates to community activity e.g. at a faith group (G Chanan, Searching for Solid Foundations (London: ODPM, 2003)). In this paper, a broad definition will be adopted and both civil and civic society will be used as interchangeable descriptors.

3 FCO, Implementing the Cross Cutting Review on the Role of the Voluntary and Community Sector in Service Delivery (London: FCO, 2004).

4 Rt Hon. Alan Milburn MP, “Let charities run public services”, The Guardian, Thursday, 6 May 2004.

5 Rt Hon. Paul Boateng MP, The Role of the Voluntary and Community Sector in Service Delivery - A Cross Cutting Review (London: HM Treasury, 2002), p. 3.

6 For an authoritative exploration of the contemporary state of the social housing sector, and the academic and policy debates which underpin it, see D Cowan and M McDermont, Regulating Social Housing: Governing decline (Abingdon: Routledge-Cavendish, 2006).

7 For an exhaustive survey of the welfare state see P Malpass, Housing and the Welfare State: The development of housing policy in Britain (London: Palgrave Macmillan, 2005). In relation to the problems of housing the vulnerable and other groups, see, e.g. P Malpass, Housing Associations and Social Policy (Basingstoke: Macmillan, 2000). 
contextual analysis of housing policy ${ }^{8}$ and alternative systems or solutions beyond the involvement of charities; this has been explored in the voluminous literature on social housing elsewhere. ${ }^{9}$ Instead, this article seeks to explore the role played by charities alone ${ }^{10}$ in providing housing and housing services to vulnerable groups, although the discussion should be of wider interest to all those concerned with service delivery and policy for vulnerable individuals.

The genesis of this paper arose from an ESRC-funded empirical research project, entitled Housing the Mentally Vulnerable: The Role of Charities. ${ }^{11}$ The qualitative data was sought by carrying out a series of 34 structured and semi-structured interviews with charitable housing associations, housing and mental health support groups, and legal experts. ${ }^{12}$ In exploring the nature and scope of charitable involvement in housing this group, the work revealed that charities play a very important, and surprisingly extensive, role. Coupled with concern in the sector that charities might be struggling with the increased demands of provision in many different spheres including housing, ${ }^{13}$ this prompted questions as to whether such significant charitable involvement in housing the vulnerable is as beneficial to users and providers as it first appears.

It is important to state from the outset that this paper will not seek to argue that charities are poor housing and support providers; such an argument would be difficult to sustain in the face of clear evidence to the contrary. ${ }^{14}$ Similarly, charitable organisations will not be compared with other housing providers to consider which might provide a better level of service; the service charities provide is recognised as both important and worthwhile. ${ }^{15}$ This paper does not suggest that these activities should be curtailed or that charities should be removed from service provision and replaced by other bodies. The aims are more modest.

This paper simply seeks to re-examine the benefits that charities bring to housing the mentally vulnerable in context. While it is not contested that many benefits will derive from charitable involvement, such as greater social cohesion and more responsive services, these benefits cannot simply be taken for granted. It is a trite proposition that some charities are better run, and provide a better service, than others; variability across any sector or group of similar organisations is to be expected. In practice, it is suggested that some of the benefits that the sector brings to the vulnerable may get lost or diluted in direct provision, either due to these organisational variations or because of the demands placed on organisations running such a housing service. Although many of the difficulties faced in

8 See D Cowan, Housing Law and Policy (London: Macmillan, 1999). For an update from 1999, see D Mullins and A Murie, Housing Policy in the UK (London: Palgrave Macmillan, 2006).

9 Cowan and McDermont, Regulating Social Housing (n. 6 above); Malpass, Housing and the Welfare State; and Malpass, Housing Associations (both n. 7 above).

10 Charities, as distinct from other not-for-profit or non-governmental organisations, enjoy fiscal and other advantages from their registration as charities - this is explored below.

11 Award Ref: RES-000-22-0286.

12 See W Barr and N Glover-Thomas, Housing the Mentally Vulnerable: The role of charities (Liverpool: Charity Law Unit, 2005). This report, hereinafter referred to as The Report, presents an analysis of the findings and some recommendations for good practice. It is freely available to download in a variety of formats from the Charity Law Unit website: www.liv.ac.uk/law/clu.

13 See Charity Commission, Stand and Deliver: The future of charities delivering public services (February 2007). This piece of research, which publishes the findings of a survey of over 3800 charities, can also be accessed at the Charity Commission's website: www.charitycommisison.gov.uk.

14 The very success of the charity (and wider voluntary) sector in providing key services is part of the attraction for increasing their role in public service provision (see nn. 1, 3, 4 and 5 above). See also ACEVO, Replacing the State: The case for third sector public service delivery (London: ACEVO, 2003).

15 See The Report, chs 3 and 5, passim. 
housing the vulnerable, such as joint working, are germane to any provider, charitable or otherwise, some aspects will have a particular resonance or impact on charities. ${ }^{16}$ Moreover, it cannot be guaranteed that those charities which currently provide benefits will always manage to do so. This article will explore the possibility that for many charities the increasing demands on them to provide services may be more than their infrastructure and resources can withstand. It will be argued that, while charities offer an excellent and necessary supplementary housing service, any further extension to their role could be potentially damaging to the charities themselves and the tangible benefits associated with charitable involvement may be lost if greater pressure is placed upon them.

In order to set the context for discussion, it is necessary to provide a sketch of charities and the social housing sector, before considering the very tangible benefits of charitable involvement in housing the vulnerable, both at societal level and at the level of provision.

\section{The role of charities}

For the purposes of this paper, and the research project which prompted it, the term "mentally vulnerable" comprises those suffering from clinically recognised mental disorders, such as schizophrenia; those with a form of organic brain malfunction, such as dementia or brain damage following injury; and those with a learning difficulty. ${ }^{17}$

The contemporary framework of social housing provision is the subject of a rich vein of academic writing across a variety of disciplines, and the authors cannot hope to add anything of value to this body of work here. ${ }^{18}$ It is already well documented that the social housing sector, which provides support for the mentally vulnerable, is shrinking and is increasingly being viewed as a "sector of last resort", 19 and that, within it, provision for the vulnerable is complex. ${ }^{20}$ The influence of policies such as community care, ${ }^{21}$ mean that it is now a matter of record that there is a paucity of suitable housing stock, ${ }^{22}$ and that housing and support services are inadequately funded. ${ }^{23}$ It is also well documented that social housing provision has become fragmented, with local authorities discharging housing duties through registered social landlords (RSLs) or non-registered housing associations

16 E.g. charity governance can be problematic, and this may weaken an organisaton in responding to the demands of joint working, as internal disputes may take precedence over the need to build strong working relationships. This is explored in full below.

17 This definition, which is non-exhaustive and does not cover all groups falling within s. 1(2) of the Mental Health Act 1983, deliberately excludes those with "psychopathic" disorders; otherwise known as personality disorders.

18 It should be noted that the focus of this piece is based on the English housing sector. While the scope and nature of the jurisdiction, and the applicable housing law, is different in Northern Ireland, the particular issues relating to housing the mentally vulnerable are likely to be the same, so that the differences will be small. If a comparative approach were sought, it would be more illuminating to evaluate a more distinctive and further removed approach to social housing and charity, such as in the US, where the scale and nature of responses will differ in substance rather than detail.

19 C Kiddle, The Impact of the Large-Scale Voluntary Transfer of Local Authority Housing Stock on the HA Sector, Sector Study 17 (London: Housing Corporation, 2002), p. 8. See Cowan and McDermont, Regulating Social Housing (n. 6 above) for an exploration of the debates surrounding the very existence of the social housing sector.

20 For an overview of the framework, see N Glover-Thomas and W Barr, "Housing an individual: property problems with the mentally vulnerable" in A Hudson (ed.), New Perspectives on Property Law, Human Rights and the Home (London: Cavendish, 2003).

21 For a general discussion of the implementation and operation of the community care policy, see S Richards and R Smith, Community Care: Policy and practice (London: Palgrave Macmillan, 2003).

22 See D Cowan, "Accommodating community care" (1995) 22 JLS 212.

23 There have been a number of new initiatives and funds to underpin service provision, including the Supporting People Fund, and the Futurebuilders Fund. For a clear history of these developments see Malpass, Housing and the Welfare State (n. 7 above) and Cowan, Housing Law and Policy (n. 8 above). 
rather than directly housing individuals. Market pressures have meant that most medium to large housing providers have become general housing providers, ${ }^{24}$ so that special needs are met either by smaller, more specialist providers, or by agencies or bodies working to provide services alongside housing.

The differing needs presented by the mentally vulnerable require expensive and individually tailored support services, administered either as floating support in mainstream accommodation or through supported housing projects. ${ }^{25}$ Some individuals will require long term-care in a supported environment, while others may move through a spectrum of needs and services to reach the goal of independent living in a self-contained environment. Matching the vulnerable to housing is the job of a number of agencies, including social services, local health authorities, support agencies, such as homelessness charities, or even other housing providers; particularly where a placement does not currently work. ${ }^{26}$

So, what is the role of charities? While it might be thought that charities are only of residual importance in this sector, as many housing associations have thrown off charitable status in recent years, ${ }^{27}$ it is in the role of specialist provider of services to the mentally vulnerable that they retain importance. Research demonstrates that 90 per cent of services to the mentally disordered are provided through housing associations or charities, with only 10 per cent direct involvement by local authorities themselves. ${ }^{28}$ Specifically, the ESRC project found that charities provided a wide spectrum of housing and housing support services to the mentally vulnerable, from supplying housing and all accompanying services, through to simply providing the support to other organisations. ${ }^{29}$ These services ranged across a broad range of need, from offering temporary accommodation to providing more permanent arrangements and/or services. Nevertheless, despite many organisations occupying multiple roles or running numerous projects, the predominant role identified was as housing manger and/or service provider to housing associations.

It is therefore as service providers and/or partners to other housing bodies and as direct service providers that the role of charities is best understood and it is in this broad sense that housing charities will be referred to here.

Finally, for the purposes of this discussion, what are charities? Charitable bodies ${ }^{30}$ are organisations which are distinct from the voluntary sector at large. ${ }^{31}$ They are registered

24 See J Alder and C Handy, Housing Associations: The law of social landlords (London: Sweet \& Maxwell, 2002).

25 For an analysis of the funding of support services and the difficulties faced in providing these supported housing projects, and some suggestions to meet these concerns see H Carr, "'Someone to watch over me': making supported housing work" (2005) 14(3) SLS 387.

26 See The Report, pp. 47-9 for a list of the bodies involved in housing the vulnerable.

27 See further D J Hughes and S Lowe, Public Sector Housing (London: Lexisnexis, 2000). Currently, there are 392 charitable housing associations registered with the Charity Commission, not including almshouses or provident societies which are exempt charities within Sch. 2 of the Charities Act 1993.

28 ODPM, Local Authority Supporting People Returns for England on Supply of Housing and Support Services, (London: ODPM, 2002).

29 The Report, ch. 3.

30 The majority of charities are set up as trusts, but a charity can, however, take a variety of forms, not limited to the trust - see further J Warburton (ed.), Tudor on Charities 9th edn (London: Thomson Sweet \& Maxwell, 2003). The Charities Act 2006 introduces a new form or vehicle for charitable companies - the Charitable Incorporated Organisation (CIO) - see Charities Act 2006, ch. 8, s. 34. Some sections of this legislation (including CIOs) are not yet in force; a full implantation plan can be found from the Office of the Third Sector website: www.cabinetoffice.gov.uk/third_sector/law_and_regulation/implementation_aspx.

31 The third or voluntary sector, as a whole, is estimated at 500,000 organisations in Britain, of which charities are a much smaller proportion - see Exploring the Third Sector (n. 1 above). 
with the Charity Commission ${ }^{32}$ and enjoy the fiscal and other advantages associated with charitable status. ${ }^{33}$ To be eligible for registration, such organisations must be of charitable character; they must have as their object a recognised charitable purpose, ${ }^{34}$ must be for the benefit of the public ${ }^{35}$ and be wholly and exclusively charitable. ${ }^{36}$ It is the legal relationship between the giver and recipient of charity that the law protects, not the act of giving. ${ }^{37}$ Charities may also not change their objects without the consent of the Charity Commission, unless their objects are already sufficiently well drafted to allow flexibility in fulfilling their charitable purposes. ${ }^{38}$

In the past, the importance and value of charities have been severely questioned; this stems from as far back as 1978, when the Wolfenden report was commissioned to consider the future of the charity sector following the establishment of the welfare state. ${ }^{39}$ It concluded that charities remained an important force for societal good. Recent initiatives ${ }^{40}$ have focused on improving and modernising charities and charity law, ${ }^{41}$ but the core concept of charities has survived intact.

\section{Benefits of charitable involvement in housing}

\section{SOCIETAL BENEFITS}

Charitable activity, in any field, is perceived as largely beneficial, allowing for a healthier society with greater social cohesion. ${ }^{42}$ Similarly, all charities contribute to civil renewal and are an essential component of social provision. Housing charities thus share in these structural characteristics of charitable endeavour. To evaluate meaningfully these social

32 Unless they were exempt under Sch. 2 of the Charities Act 1993. This section has been amended by the Charities Act 2006, ss. 11-14 and Sch. 5. These sections ensure that such charities are now monitored for their compliance with charity law; in the housing sector this will be the job, in most cases, of the Housing Corporation acting as regulator.

33 For an excellent summary of these advantages, see P Luxton The Law of Charities (Oxford: OUP, 2001), ch. 2.

34 The Charities Act 2006, s. 2, introduces a statutory definition of charitable purposes, listing 15 different purposes, replacing the enduring "four heads" from Commissioners for Special Purposes of the Income Tax v Pemsel [1891] AC 531. The latest statutory definition, contained in the Charities Act 2006, does not significantly alter the basis of the definition, but modernises the heads of charity to include activity which has already been recognised either through the case law or the decisions of the Charity Commissioners at registration.

35 Public benefit will no longer be presumed for any charitable purpose and must be proved in all cases for a charity to be registered and function as a charity - Charities Act 2006, s. 3. The Charity Commission is working towards a definition of public benefit for all purposes (s. 4) and is aware that "one size will not fit all".

36 This requirement means that a charity must act within its defined charitable purposes, and must not engage in non-charitable activity - for a good exploration, see Warburton, Tudor on Charities (n. 30 above).

37 Luxton, The Law of Charities (n. 33 above).

38 See, generally, Warburton, Tudor on Charities (n. 30 above).

39 Report of the Wolfenden Committee, The Future of Voluntary Organisations (London: HMSO, 1978).

40 See, e.g. the Charity Commission, Review of the Register: www.charity-commission.gov.uk/ publications/ccpubs2.asp.

41 At the time of writing, the Charities Act 2006 is mostly partly in force. See the Charity Commission website for a detailed summary of the impact of these changes: www.charity-commission.gov.uk/spr/charbill.asp.

42 It must, however, be noted that these elements which have been identified as core benefits from charitable activity are not set in stone nor are they uncontested as potential benefits. There remains an ongoing unsettled debate particularly around social capital and social cohesion. For a more detailed analysis of these concepts, see F Fukuyama, "Social Capital and Civil Society" (paper presented at IMF Conference on Second Generation Reforms, 1999), available at: www.imf.org/external/pubs/ft/seminar/1999/reforms/fukuyama.htm; and P Bernard, Social Cohesion: A critique, CPRN Discussion Paper no. F|09 (Ottawa: CPRN, 1999), p 2. 
benefits it is necessary to consider charitable involvement in the creation of strong communities, measured through social capital and social cohesion.

\section{SOCIAL CAPITAL AND CHARITABLE INVOLVEMENT}

The central premise of social capital is that social networks have value. Social capital refers to the collective value of all social networks and recognises the benefits that arise from reciprocal working and cooperation and relationships of trust within a community. ${ }^{43}$ Putnam considers social capital to be "networks, norms, and social trust that facilitate coordination and cooperation for mutual benefit". 44 Fukuyama, however, suggests that social capital should not be simplistically interpreted as only offering benefits to society but rather that social capital should be measured in terms of both the creation of negative and positive externalities. ${ }^{45}$ Where a group of organisations and bodies create a support network for those in need, on the face of it, this can only be a positive endeavour. 46 Groups, organisations and other bodies have the potential for encouraging internal cohesion from within, for example, employees and volunteers may have a different view of a charitable organisation to a mere donor. This internal cohesion may be brought about at the expense of those who are not part of the organisation. The achievement of positive externalities is essential in the creation of a beneficial form of social capital that can have a marked effect upon social welfare. Thus, where charitable and other voluntary sector organisations manage to achieve a "radius of trust", ${ }^{47}$ which results in positive externalities, then a form of social capital is created that binds communities together and offers a framework of support to more vulnerable members of society. The type of housing support and activity undertaken by charities dealing with the mentally vulnerable is, in theory, a clear expression of this. ${ }^{48}$

Examples of the potential positive externalities ${ }^{49}$ that such work can create include outreach efforts which seek to bring vulnerable individuals together and to reduce levels of isolation that are common among such groups, as "where social trust is often low, the activities of third sector organisations can help to build pockets of trust and cooperation, leading to a positive cycle of social capital development". 50 The Office for National Statistics confirmed this view in $2001 .{ }^{51}$ On a less direct level, the existence of social capital which has been brought about by positive externalities contributes to a variety of social changes, such as lower crime rates, better and higher educational achievements, greater equality of income and better health.

\section{Social cohesion and the creation of strong communities}

A consensus on the definition of "social cohesion" remains illusory 52 and subject to continuing academic debate. Nonetheless, it is almost universally accepted that anything which may increase the level of social cohesion is viewed as a beneficial element to a

43 A C Brooks, "Does social capital make you generous?” (2005) 86 Social Science Quarterly 1.

44 R D Putnam, "Bowling alone: America's declining social capital” (1995) 6 Journal of Democracy 65, p. 67.

45 Fukuyama, "Social capital" (n. 42 above).

46 J Coleman, "Social capital in the creation of human capital" (1988) 94 American Journal of Sociology 95.

47 Fukuyama, "Social capital" (n. 42 above).

48 See The Report, ch. 3, pp. 23-36, which details the extent and nature of the various housing services offered by charities to this client group.

49 H Begum, Social Capital in Action (London: HCVO, 2003).

50 Exploring the Third Sector (n. 1 above), p. 41.

51 Social Analysis and Report Division, Social Capital - A review of the literature (London: Office for National Statistics, 2001).

$52 \mathrm{C}$ Beauvais and J Jenson, Social Cohesion: Updating the state of the research, CPRN Discussion Paper no. F|22 (Ottawa: CPRN, 2002). 
healthy, civil society. The agreed constituent elements are: "common values and civic culture; social order and social control; social solidarity and reductions in wealth disparities; social networks and social capital, and territorial belonging and identity". ${ }^{53}$ From this, a socially cohesive society (and therefore something all societies should seek to be) is one where common values are shared among individuals that allow them to identify common aims and share codes of behaviour through which to conduct their relations with one another. Such a society is likely to have a higher degree of social interaction within the communities that make up society as a whole. ${ }^{54}$ The Council of Europe ${ }^{55}$ views social cohesion to comprise a sense of belonging: to a family, a social group, a neighbourhood, a workplace, a country.

The simple existence of the charitable sector is deemed, for the most part, to have a positive role to play in a socially cohesive society. Nevertheless, the Joseph Rowntree Foundation found in 1999 that in four disadvantaged communities across Britain (Teeside, Liverpool, East London and Nottingham) social cohesion or the lack of it was not the primary reason behind difficulties that tended to be experienced. Rather, problems tended to stem from poverty which led to community commitment diminishing. ${ }^{56}$ Poverty and other similar social problems are commonly tackled by charitable organisations and it is this, arguably, which fuels the view that charitable and voluntary sector organisations are an essential component to the creation of strong communities. Housing the vulnerable is one such area of obvious need being met. For example, without the involvement of housing charities, some mentally vulnerable individuals fall through the statutory gaps ${ }^{57}$ and become homeless or disenfranchised from appropriate care and support. ${ }^{58}$

Volunteering, which is at the heart of community involvement in charities, also has an important role to play. The Volunteering Code of Good Practice defines volunteering as actions which consist of: a) the commitment of time and energy for the benefit of society; b) an expression of citizenship; c) undertaken freely and by choice, without concern for financial gain. However, where individuals volunteer their services to organisations there is a clear quid pro quo in terms of the giving and receiving of benefit. Services offered free of charge to charitable organisations allow them to operate at a low cost and enables the flow of funding to be directed to the provision of services rather than to fund the organisation's infrastructure. A volunteer may also benefit in several ways. ${ }^{59}$ For example, "volunteering has a clear, positive benefit to the labour market and economy" 60 as it enables the development of an individual's self-esteem, through the giving of new experiences, allowing the development of new skills and providing an important source of confidence

53 Beauvais and Jenson, Social Cohesion (n. 52 above), p. 2.

54 A Kearns and R Forrest, "Social cohesion and multilevel urban governance" (2000) 37 Urban Studies 995, p. 999.

55 Council of Europe, A Report on the Brainstorming Session Held in November 1999 on "Education for Democratic Citizenship and Social Cohesion" (1999) p. 2, see http://culture.coe.fr/postsummit/citizenship/concepts/ erap99_60.htm.

56 See Joseph Rowntree Foundation, Social Cohesion and Urban Inclusion for Disadvantaged Neighbourhoods (York: JRF, 1999).

57 Problems with a satisfactory legal definition of "homelessness" and a conflict between the priority need (s. 189) and intentional homelessness (s. 191) provisions under the Housing Act 1996 (unresolved by the Homelessness Act 2002) contribute to a situation where some mentally vulnerable individuals slip through the current statutory duties to be housed - see Glover-Thomas and Barr, "Housing an individual" (n. 20 above) for a more in-depth discussion.

58 The Report, pp. 6-8.

59 Exploring the Third Sector (n. 1 above), passim.

60 Ibid., p. 41. 
and social contact. ${ }^{61}$ Housing charities, as with all others, will have volunteers as part of the workforce, whether behind the scenes in the administration of the organisation, or in providing the services themselves.

\section{BENEFITS AT THE LEVEL OF PROVISION}

In addition to the wider benefits to society, charities are also regarded as beneficial contributors to service provision itself. This involves examining some of the major characteristics of charities; in particular the fact that they are perceived as value driven, trusted, independent, responsive, innovative and fill recognised gaps in provision. Evidently, these characteristics are applicable to any charity; however, their distinctiveness marks the difference between charities and other housing providers, who do not have charitable status and thus do not enjoy such features.

\section{Value-driven}

Charitable organisations focus upon social, economic and cultural objectives that benefit society. Charities are often described as "value-driven" 62 in that they exist to promote and reflect their values or objectives rather than to make profit, reinvesting any operating surpluses to enhance service provision. This approach enables charities to bring different aspects of society together, drawing on the participation of volunteers, encouraging social cohesion and community participation. Similarly, the focus of charitable organisations is primarily on the needs of those they seek to serve. This, in conjunction with the "valuedriven" approach, enables practical support to be offered at ground level to those in need. Indeed, data suggests that the nature and duration of housing and the support offered by charities to the mentally vulnerable is tied directly to the functions and key objectives of the charitable organisation. ${ }^{63}$

\section{Trusted}

Charities are also generally perceived as trustworthy organisations. It is said that "trust is the voluntary sector exchange rate", 64 and is connected to the core ethos and social objectives of many charities. An effective charity is seen as accountable, not only because it accounts to regulators who can exercise direct sanctions against recalcitrant organisations, ${ }^{65}$ but also because it "is accountable to the public and other stakeholders in a way that is transparent and understandable". ${ }^{66}$ In taking account of the needs of users as stakeholders, charities are providing a "voice" to them, by ensuring their needs are met in service provision. 67 Charities also play a role in providing "choice" to users, as the existence of an alternative service by a charity, and the possibility that it might be taken up in preference to a service from a non-charitable body, acts as a motivating factor to the non-charitable body to take account of the needs of users when designing and delivering services. ${ }^{68}$

61 Voluntary Sector National Training Organisation, Voluntary Sector Workforce Development Plan (London: VSNTO, 2001). Report available at www.vsnto.org.uk/development \%20plan.pdf.

62 Exploring the Third Sector (n. 1 above), para. 2.6.

63 The Report, p. 23.

64 NCVO, "Blurred vision" (1998) (1) Research Quarterly, January.

65 P Day and R Klein, Accountabilities for Five Public Services (London: Tavistock, 1987).

66 Charity Commission, CC60, The Hallmarks of an Effective Charity (London: Charity Commission, 2004).

67 See Public Administration Select Committee, Fourth Report of Session 2004-05: Choice, voice and public services (London: House of Commons, 2005), pp. 49-51.

68 A Blackmore, H Bush and M Bhutta, The Reform of Public Services: The role of the voluntary sector (London: NCVO, 2005), p. 17. 
It is these factors which contribute to the importance and effectiveness of the charity "brand", ${ }^{69}$ as charities "have a strong public image . . J Just knowing that an organisation is a charity is often enough to give the public confidence to donate money to it." 70 Housing charities are dependent on donation funding, alongside more direct funding streams, ${ }^{71}$ so the importance of trust and brand remain essential.

\section{Responsive}

Another recognised aspect of charitable organisations is their ability to focus upon the users of their services and respond to their needs. Charitable organisations are generally directed by the desire to meet the needs of and to improve the well-being and opportunities available to those who receive their services. ${ }^{72}$ Charities are often established and run by those with direct experience of a particular need or disadvantage, allowing them to reach out to others more effectively, and even encourage current users of the service to facilitate its delivery in the future. Charity workers at both grass-roots and organisational levels often have a special understanding of, and commitment to, the needs of the community the charity seeks to serve. The ways in which charities are organised may also allow greater responsiveness to the needs of its clients. They often have fewer structural constraints in terms of their aims and the way in which they can carry these out, and because other "organisations often have multiple goals and stakeholders, and can have a more informal or 'ambiguous' organisational structure, this may allow them to respond better to users with multiple disadvantages". ${ }^{73}$ This is evident in housing the vulnerable, as charities can provide additional specialised services, including training or work schemes, developed to meet specific user needs. ${ }^{74}$ Moreover, the involvement of users in the operation of these housing organisations ${ }^{75}$ and the fact that many organisations have evolved to meet changing needs in the housing sector ${ }^{76}$ convincingly demonstrate this key aspect of their appeal.

\section{Innovative}

Charities are recognised as pioneers in the establishment of new approaches to social problems and are said to innovate in two particular ways: by finding better ways to deliver a service (process innovation) and by developing new services in response to need (product innovation). ${ }^{77}$ This capacity to innovate stems from the comparative freedom charities have to take risks, without which there is very little innovation. ${ }^{78}$ The commercial or "for-profit" sector is the more natural home of innovation, as market forces demand that organisations take risks as they may otherwise face merger with more aggressive and innovative rivals.

69 Strategy Unit, Private Action, Public Benefit (London: TSO, 2002), ch. 6, "Building public trust and confidence and supporting the sector in improving performance".

70 Strategy Unit, Private Action, p. 14.

71 The Report, pp. 50-3.

72 S Domberger and P Jenson, "Contracting out by the public sector" (1998) 13 Oxford Review of Economic Policy 67.

73 D Billis and H Glennerster, "Human services and the voluntary sector: towards a theory of comparative advantage" (1998) 27 Journal of Social Policy 79.

74 The Report, pp. 29-30.

75 C Cooper et al, "Community involvement, housing and equal opportunities", in C Cooper and M Hawtin (eds), Housing, Community and Conflict: Understanding resident "involvement" (Aldershot: Arena, 1997).

76 The Report, p. 27, which demonstrates that some housing organisations have splintered into smaller, more focused groups or have evolved or changed their focus to meet new needs or follow new funding priorities. There are questions, however, over the legality of some of these actions, which are explored below.

77 Exploring the Third Sector (n. 1 above), p. 31.

78 M Bolton, Voluntary Sector Added Value. A discussion paper (London: NCVO, 2004). 
However, in relation to social welfare, pursuit of profit and the need to streamline costs in service delivery, often results in reduced service and stifles innovative thinking or approaches by for-profit organisations. An example of this is the failure of the for-profit sector to provide a sustainable private rental housing market to deal with social housing as an alternative to the public sector, despite direct government incentives to do so. ${ }^{79}$ Charities, on the other hand, given their focus and responsiveness, tend to see process and product innovation in service delivery as important goals. In relation to housing the mentally vulnerable, there is clear evidence of such innovation - the empirical data demonstrate process innovation as methods are developed by some charities to enhance joint working to the benefit of service provision for their beneficiaries. ${ }^{80}$ Product innovation is also present within this sector as many providers also offer additional services, owing to the particular needs of their vulnerable client group. ${ }^{81}$

\section{Filling service gaps}

The final characteristic of charities that directly benefits service users is the charities' role in filling gaps in existing service provision, however caused; politics and social agendas do not impinge on the need to deliver the required service to an otherwise disenfranchised group. Some commentators argue that filling gaps in service provision is beyond the remit of charities, ${ }^{82}$ but charitable organisations have undoubtedly been viewed as bodies which have met social needs that are not provided through other means, as their historical role in housing demonstrates. It may be argued that filling service gaps for many charities is a clear part of their practical role and one which, if ignored, would be counter to their charitable objectives and motivation.

In housing the vulnerable, this gap-filling role is evident. The conflict between the priority need and intentional homelessness provisions under existing homelessness duties on local authorities means that many individuals with difficult or challenging behaviour fall through the statutory net and are classed as "intentionally homeless", 83 meaning that there is no duty to rehouse the individual, just to provide temporary accommodation and assistance in locating housing. ${ }^{84}$ Coupled with the implementation of the community care policy - which ignored the need to provide adequate housing support ${ }^{85}$ and has contributed to a paucity of suitable stock for social housing - clear service gaps have emerged, to deal with which charities have either changed their objects, merged or been created. ${ }^{86}$

\section{Re-examining the benefits}

The potential advantages of charitable involvement already outlined are, it is suggested, based on the concept of the model charity - the expertly run and financed charitable organisation which innovates and plays a deliberate and focused role in enhancing service provision and wider community interests, benefiting social capital and cohesion. In fact, many charities do not meet this ideal, but may show different beneficial characteristics, though not all at once. Charities are not perfect, nor is the housing environment in which

79 See S Merrett, Owner Occupation in Britain (London: Routledge \& Keegan Paul, 1982).

80 The Report, ch. 4.

81 The Report, p. 29.

82 Milburn, "Let charities" (n. 4 above).

83 See N Glover, "Mental health and housing: a crisis on the street?" (1999) Journal of Social Welfare and Family Law 327.

84 Housing Act 1996, s. $190(2)$.

85 Glover-Thomas and Barr, "Housing an individual" (n. 20 above).

86 The Report, p. 27. 
they have to work and it is these realities which can potentially dilute the benefits already identified. It is worth remembering that the following discussion is not intended to suggest that charities should not provide housing to the vulnerable or should be replaced by other organisations, but simply to explore how tangible the benefits of charitable involvement actually are at the level of service provision and to identify any areas of concern for any increased role in the future.

To look beneath the surface of the benefits already considered requires a discussion of provision on the ground, which has been grouped into four themes: problems in creating social capital; achieving social cohesion; considering the reality of the value-based charity; and, finally, an exploration of the public perception of charities and the charity "brand". This established, some conclusions about the impact of increasing pressure on charities to act as a vehicle of housing provision for the vulnerable can be explored.

\section{SOCIAL CAPITAL - RECIPROCITY AND THE CREATION OF SOCIAL NETWORKS}

One of the benefits which flows from social capital is the creation of social networks, through co-operation and reciprocal working, binding people and values together. This depends on charities having an effective, well-motivated and stable workforce, of either volunteers or paid employees/trustees. In conjunction with this, effective joint working practices must be established within the sector in order for seamless service provision to be possible. Without this, the building blocks of successful social networks are absent, because the necessary skills and "community" spirit within and without the organisation are lacking.

\section{Staffing issues}

If a charity is to create or maintain effective social networks, it is a trite proposition that it requires a stable workforce to do so. Of course, this is true of any housing provider, not just charities, but staffing issues are particularly problematic for the charity sector as a whole. Existing research has found, for example, that staff turnover in voluntary organisations was at 20 per cent per annum, more than for all other employment sectors. ${ }^{87}$ This creates instability, as continuity is lost, jeopardising established interpersonal relationships within and without the charity sector.

There can also be major issues in recruiting effective, skills-led staff. Paid charity employee wages can be lower than competing private industry or public sector organisations, ${ }^{88}$ but the level of skills required, and the demands on staff to complete jobs, are no less than those required in companion sectors. In the housing context itself, many charities find it intensely problematic to recruit and retain staff with appropriate levels of training, experience and commitment to the organisation's charitable objects. ${ }^{89}$ This arises because of the particularly stringent skills and experience required to deal effectively with mentally vulnerable users, poor salaries in comparison to public and private sector workers, and worker stress in dealing with difficult clients and balancing competing needs. ${ }^{90}$

Recruitment and retention can be an even greater issue in relation to volunteers, who are viewed as the lifeblood of many charities and volunteering, with its associated benefits, is a crucial element to the creation of social capital. For example, the relatively minor role of

87 K Dullahide, L Ellarby and K Smith, People Count (London: Compass Partnership, 2000).

88 Charities have recognised this as a problem, but still face difficulties in being competitive - see P McCurry, "Salary review: rich rewards?" (2003) Voluntary Sector Magazine, 7 November.

89 The Report, p. 47.

90 Ibid., p. 47. 
volunteers in the hierarchy of decision-making processes in many charities adds to feelings of discontent or exclusion and may hasten exit, ${ }^{91}$ so that skilled volunteers may be lost to related roles in the public or private sector where pay and employment benefits are greater. ${ }^{92}$

The combined effect of these staffing issues can result in problems in the provision of direct-line services by charities, either in the short term or, if unchecked, they may lead to serious damage in the longer term with the charity unable to provide some or all of its intended services. At the level of the mentally vulnerable individual, it may also mean that people with whom vulnerable adults have built up individual trust and rapport may move on, and it may take considerable time to achieve a similar level of service with a replacement provider, even where the skills base is the same or better. At organisation level, recruitment and retention can frustrate efforts to engage with the wider community and other organisations, affecting relations with partner providers, and thus have a negative impact on achieving effective networks.

Indeed, the fact that charities are essentially value driven, as identified above, might occur at the expense of matters of equal importance to service delivery, particularly the staffing issues identified. Some charities may not invest in infrastructure in the same manner or extent as a commercial organisation, preferring to spend on direct services for users. If this is so, competitive wages, training opportunities, recognisable appraisal mechanisms, transparent grievance procedures and clear retention policies may be entirely lacking or present in a rudimentary form which compounds resentment, affects retention and exacerbates disputes. ${ }^{93}$

Employment disputes are also a very common feature within charities, as research demonstrates that charities are twice as likely to become involved in employee disputes ${ }^{94}$ and employment tribunal cases are double the level of private and public sector organisations. ${ }^{95}$ There is no reason to suspect that this is any different in relation to housing charities. Triggers for these disputes may include poor personnel policies, ${ }^{96}$ a lack of clarity over dividing lines between roles in the workforce ${ }^{97}$ and uncertainty as to the status of individual workers as either volunteers or employees. ${ }^{98}$ Disputes, and potential litigation, relating to the last of these can be particularly wasteful in terms of both time and financial resources, and can impact both on motivation of the workforce within charities and the potential benefit of low running costs that using volunteers can bring. ${ }^{99}$

\section{Professionalisation}

One clear demand on modern charities is the need to professionalise, in order to compete with rival charities and private organisations, and to differentiate their service, as well as to

91 D Morris, Disputes in the Charitable Sector (Liverpool: Charity Law Unit, 2003), p. 22.

92 See The Report, pp. 46-7.

93 Morris, Disputes (n. 91 above), pp. 22 and 26.

94 Ibid.

95 I Cunningham, "Sweet charity! Managing employee commitment in the UK voluntary sector" (2001) 23 Employee Relations 226.

96 Morris, Disputes (n. 91 above). This is particularly a problem for smaller charities, or those which have undergone a sharp rise in employee numbers (e.g. on merger).

97 This is particularly true in the division between job descriptions for paid staff, volunteers and independent contracts - see Morris, Disputes (n. 91 above), p. 23 and ch. 4 generally.

98 The presence of any form of payment (e.g. an honorarium) may transform what the charity believes to be a volunteer into an employee, with the consequent legal statutory rights - see D Morris and J Warburton, Legal Issues in Charity Mergers (Liverpool: Charity Law Unit, 2001).

99 See M Restall, "Righting wrongs" (2002) Volunteering Magazine, March. 
improve internal governance. ${ }^{100}$ Charities are forced to take account of market factors, including funding opportunities, potentially to expand the service they offer thereby widening any gaps with rival organisations. In social housing, ${ }^{101}$ this "professionalisation" has crucially led many charities to abandon charitable status altogether while those that remain charities have done so either to use charitable funds to replace willing volunteers with paid, professional employees or to delegate certain specialised functions to other organisations. ${ }^{102}$ In many cases, those organisations which have been deregistered as charities are now not-for-profit organisations, rather than private organisations, that have been forced to become more commercially or professional orientated owing to reduced state housing and public funding and to increased competition and diversification of activities instigated by housing associations. ${ }^{103}$ This raises some interesting questions over the mooted positive externalities of charities working jointly with other agencies through participation and consultation. ${ }^{104}$ The increasing trend towards professionalisation would indicate that competitive, market tendencies are potentially prevailing within the sector and rather than joint working practices being encouraged in order to provide a seamless and comprehensive service, charities may be focusing their aims and internalising their activities to the detriment of social capital formation and the creation of social networks.

\section{Multi-agency working}

Professionalisation may have a potentially damaging impact upon joint working. Yet, despite this, the concept of joint working to facilitate public service delivery has become central in policy development over recent years. ${ }^{105}$ Within health and social care, a clear shift away from central provision is evident, being replaced by authorities commissioning services from other sectors. 106 This move towards service outsourcing necessitates the harnessing of joint working practices; effective joint working between agencies depends upon viable delivery processes, social networking and cooperation between agencies, active within service delivery and management. ${ }^{107}$ Effective joint working aids the creation of social capital because where communication channels are open and agencies are achieving their delivery aims, a rich network of cooperating providers is likely to be present within the service framework.

Nevertheless, recent research indicates that relations across organisations are not so easy to establish and frequent miscommunication can lead to serious problems, prompting the conclusion that effective joint working between agencies is more of an aspirational goal

100 See, e.g. D Morris and J Warburton (eds), Charities, Governance and the Law: The way forward (Oxford: Keyhaven, 2003).

101 For an empirical exploration of problems of governance within housing bodies generally, see D Cowan, M McDermont and J Prendergrast, Governing and Governance: A social housing case study, Working Paper no. 06/149 (Bristol: CMPO, 2006).

102 Ironically, charities themselves are the delegatees in relation to services for the mentally vulnerable, as many of the ex-charitable RSLs are general providers only - see The Report, ch. 3.

103 M. Lewis, "Non-profit housing agencies: 'reading' and shaping the policy agenda", in M Harris and C Rochester (eds), Voluntary Organisations and Social Policy in Britain (London: Palgrave Macmillan, 2000).

104 It also suggests, perhaps, that the limits imposed by charity law and regulation are too stringent to allow for competition in the wider housing environment, but that is an issue for further study elsewhere - see, e.g. Charities and Not-for-Profits: A modern legal framework (London: NCVO, 2003).

105 Home Office, The Compact, Cm 4100 (London: TSO, 1998).

106 Carr, "Someone to watch over me" (n. 25 above), pp. 387-408.

$107 \mathrm{~J}$ Secker and K Hill, "Broadening the partnerships: experiences of working across community agencies" (2001) 15 Journal of Interprofessional Care 341. 
than a practical reality. 108 In the words of Staite and Martin: "Working together is not easy." 109 That this affects charities in delivering housing to the vulnerable is clearly evidenced by the research, which demonstrates that there are some very real barriers which make it immensely difficult to enhance and maintain effective social networks and cooperative working. Briefly stated, these include inadequate forums to meet and discuss cases, mistrust of the different professionals involved, limited communication and an unwillingness to disclose information, time constraints, and different professional cultures feeding into the meeting of different professional goals and agendas. ${ }^{110}$ These problems are compounded by current policy initiatives, which seek to enhance multi-agency working by focusing almost exclusively on organisational cooperation, without recognising the importance of the individual in inter-professional relationships. ${ }^{111}$ Currently, joint working within the context of housing provision and the mentally vulnerable seems far from perfect. If the "joined-up approach" 112 in public service delivery is to remain a top policy priority, improvements will be needed to respond to and counter the barriers to joint working that currently exist. Obviously, such problems are generic to any housing provider working in this sector, and are not charity specific. Nonetheless, the impact should not be overlooked.

Having considered the practical difficulties which exist in realising social capital and, at an operational level, related problems associated with direct service provision within some charities, it is necessary next to consider whether housing charities aid social cohesion in practice.

\section{SOCIAL COHESION - LINKS BETWEEN CHARITIES AND THE WIDER COMMUNITY}

Elements of a socially cohesive society are greater community confidence, self-esteem and social engagement. Charities play a significant role in this area. However, this involvement by charities must be measured against practical experience, with recognition that some harmful influences exist which may damage social cohesiveness.

\section{Antisocial behaviour and the community}

One such factor is the divisive impact of antisocial behaviour on communities; a wellpublicised phenomenon and one that is a major issue for all housing providers. ${ }^{113}$ Owing to some common behavioural traits associated with and exhibited by many mentally vulnerable individuals, such as delusional beliefs, hallucinations or behaviour linked to personality disorders, antisocial behaviour can be a particular issue for this group. ${ }^{114}$ Research ${ }^{115}$ demonstrates that behaviour can range from simple noise pollution, through a

108 There are numerous examples of research exploring the difficulties and barriers to achieving good multiagency working. See, e.g. National Audit Office, Delivering Efficiently: Strengthening the links in public service delivery chains (London: NAO, 2006); and B Hannigan, "Joint working in community mental health: prospects and challenges" (1999) 7 Health and Social Care in the Community 25.

109 C Staite and N Martin, "What else we can do? New initiatives in diversion from custody" (1993) 157 Justice of the Peace 280.

110 The Report, pp. 47-9.

111 B Hudson, "Interprofessionality in health and social care: the Achilles' heel of partnership?” (2002) 16 Journal of Interprofessional Care 7.

$112 \mathrm{~J}$ McHale, "Standards, quality and accountability - the NHS and mental health: a case for joined up thinking?" (2004) 4 Journal of Social Welfare and Family Law 369.

113 For an excellent analysis of some of the problems and concerns around existing anti-social behaviour as well as a definition of which behaviours are covered, see H Carr, The Anti-Social Behaviour Act 2003 (Bristol: Jordans, 2004).

114 See, e.g. Cabinet Office Social Exclusion Unit, National Strategy for Neighbourhood Renewal, Report of the Policy Action Team 8: Antisocial behaviour (London: Cabinet Office, 2000).

115 See, further, C Hunter, Tackling Anti-Social Behaviour (London: Lemos and Crane, 2002). 
lack of awareness of the impact of individual actions, to more serious criminal offences such as arson. Therefore, management of antisocial behaviour is something common to all housing providers, not just charities, and there are several remedies available, depending on the nature of the occupation arrangement involved. ${ }^{116}$ It is possible to overcome these issues, but it is not always easy to do so. ${ }^{117}$ The Law Commission has recognised the difficulties in managing anti-social behaviour from a provider's perspective, and has proposed new powers to deal with such issues in the future. ${ }^{118}$

Of perhaps greater concern to social cohesion is the prevalence of antisocial behaviour emanating from the community itself towards mentally vulnerable occupiers, ${ }^{119}$ rather than the converse. The occurrence of this behaviour - which can perhaps be explained by factors such as non-optimal placement of mentally vulnerable tenants, or a lack of engagement with the local community ${ }^{120}$ - nevertheless raises doubts as to whether there is always an identifiable consensus between community values and the values of a charitable (or other) organisation carrying out its objects. More explicitly, where a charity seeks to house a person with challenging behaviour, an objective which it sees as a social good, this view may not be shared by the host community. If this is so, the placement may, in fact, be divisive, reducing social interaction and damaging social connectivity. Similarly, concentration of vulnerable groups in distinct housing schemes can create additional social problems, such as drugrelated crime; the presence of a vulnerable group can encourage exploitation and provide a captive market, ${ }^{121}$ all factors which can undermine cohesion, creating a blame culture within the community. Again, the same will be true for any housing provider wishing to place a mentally vulnerable individual within the community, but there is perhaps not the same discord with the ethos and objects of the organisation that persists within charities. This is one of the realities of provision to this vulnerable group, and, again, although charities cannot change the environment within which they operate, the impact that antisocial behaviour may have cannot simply be ignored.

What the above demonstrates is that there is a potential disparity between the views of the individuals who collectively comprise a community and the views of policy makers or service providers. Particularly, what might be deemed in the best interests of the community in a normative sense does not necessarily translate to the demographic and social picture of particular, individual communities. For example, a decision by a local authority and charitable partners to place a hostel in a particular location may reduce community choice, as, whatever the views of the community inhabitants, the hostel could still be established. ${ }^{122}$

This suggests that there may be a major difference between social cohesion as an instrument of social planning in the hands of policy makers and others and social cohesion as a concept on the ground. Charities, in providing services to the mentally vulnerable, may find themselves caught between these two competing positions and be correspondingly

116 See, in context, W Barr and N Glover-Thomas, "Housing reform - a better deal for the mentally vulnerable?" (2005) 60 Conv 207.

117 Hunter, Tackling Anti-Social Behaviour (n. 115 above).

118 Law Com. no 6781-11, Rented Homes Bill 2006, s. 51.

119 The Report, p 55. See, also, E Silver, "Race, neighbourhood disadvantage, and violence among persons with mental disorders: the importance of contextual measurement" (2000) 24 Law and Human Behaviour 449.

120 The Report, p. 55.

121 Ibid., p. 55.

122 While it is true that planning regulations allow for public objections to be aired, where a positive duty exists to create housing for vulnerable groups, it is arguable whether in the majority of cases such objections would be sustained. See, however, The Report, p. 58, which suggests that planning regulations can allow discrimination by communities against the vulnerable. 
unable both to provide the actual services they wish to or, indirectly, to produce the tangible benefits of social cohesion. That this will be true of any housing scheme for the vulnerable, whether run by a charity or not, is not the issue, as charities are one of the key vehicles for this type of housing service. ${ }^{123}$ However, what it does demonstrate is that the nature and outcome of a given activity as carried out by a charity may raise questions as to the perceived benefits of charitable involvement per se.

\section{THE VALUE-DRIVEN CHARITY}

The picture of the value-driven charity and the benefits that derive from it are characteristics of the aforementioned model charity. Such thinking ignores the practical influences and pragmatic decisions that charities are forced to make on a daily basis.

\section{Pragmatic drivers}

It is clear that in the challenging environment in which charities often work, and no more so than in housing provision for the vulnerable, it is important for charities to be flexible in how they provide services. The same could be said of any housing provider, but charities are subject to particular strictures imposed by charity law; most significantly that a charity is set up for certain, legally approved, purposes (technically, objects). ${ }^{124}$ A charity that operates outside its stated objects is acting in breach of trust and the ultimate sanction would be that the charity be investigated and/or deregistered by the Charity Commission. ${ }^{125}$ It is of prime importance that a charity's objects are wide enough to allow flexibility, as changing objects is neither simple nor guaranteed. ${ }^{126}$ For many extant charities, their object clauses are restrictive. ${ }^{127}$ This means that to act pragmatically charities often work on the margins of acceptability; carrying out a particular service or adopting a specific policy because it is in the best interests of the organisation or the users even if is just inside or outside accepted practice or a legal framework. Research into housing the mentally vulnerable highlights this very clearly, with charities seeking repossession against groups to move them on, even when they should not strictly do so: "There might be a legal position that we shouldn't actually do that . . . but we can't do that otherwise we would close down."128

Similarly, this position was echoed in relation to the adoption of short-term or introductory occupation arrangements; ${ }^{129}$ charities sometimes chose to employ them in direct defiance of housing corporation guidance or the wishes of their housing stock owner. ${ }^{130}$ This is pragmatism in its purest form, but it does carry potential concerns that charities might be in breach of the law and the governing trustees might find themselves liable for allowing the charity to act in breach. ${ }^{131}$ Whatever the direct legal consequences of such actions might be, the willingness of charities to work on the fringes of acceptability

123 ODPM, Local Authority (n. 28 above).

124 Warburton, Tudor on Charities (n. 30 above).

125 See, generally, Luxton, Law of Charities (n. 33 above). Ss. 6 and 7 of the Charities Act 2006 clarify the powers and jurisdiction of the Charity Commissioners.

126 Broadly, charities require the approval of the Charity Commission to allow for a change in objects, and this can be a time-consuming and expensive procedure, which does not guarantee success - see Luxton, Law of Charities (n. 33 above), passim.

127 The Report, pp. 77, which recommends that charities have wide object clauses to allow for changes in practice, as this was found to be the case with many of the data sample - see chs 3 and 4, passim.

128 Ibid., p. 68.

129 For an excellent summary of the complexity of the current legal framework on occupation arrangements, see Law Commission, Renting Homes (London: HMSO, 2003).

130 The Report, pp. 60-2.

131 Luxton, Law of Charities (n. 33 above). 
might be negatively perceived by the public, if such behaviour is challenged in the public domain through the Charity Commissioners. Furthermore, it might sully the reputation of charities as a partner in joint-working processes, or may, indeed, trigger or exacerbate disputes within charities themselves. ${ }^{132}$

Conversely, a lack of pragmatism and the strict pursuit of the stated charity objects can also lead some organisations to adhere to a particular form or method of delivery to meet those values, thereby obviating the benefits of innovation and responsiveness inherent in charitable activity. Loyal observance of traditional values can lead to conventional modes of delivery. The ability of a charity in these circumstances to adapt to changes in policy and funding can ossify; charities may continue to provide a particular service, even where direct funding for it is removed or changes in law or care practice make it impracticable to continue this form of delivery. It may be contended that, in housing provision, adherence to issues beyond the law as noted above is not pragmatism, but an inability to change practice to meet the demands of changing provision. This is particularly so if charities attempt to run a service for which funding is no longer available, due to changes in funding regimes. ${ }^{133}$ Of course, observance of outdated delivery methods would not be unique to charities, but in following their values, it is not unreasonable to suggest that the problem may be more prevalent in charitable organisations.

\section{Influence of board members}

The presence of values as a driver for charitable organisations can sometimes be as much of a weakness as a strength. These values frequently have at their origin the personal energies or motivations of the charity's founder members: these people may still be involved in the management decisions of charities and may be resistant to changes in practice or loss of control, even if objectively the changes are in the best interest of the charity. ${ }^{134}$ In contrast, dominant personalities within a charity may have sufficient influence to carry forward their own personal agendas, which may or may not be in the best interests or reflect the values of the charity. ${ }^{135}$ Combating the dominant direction and influence of such individuals may depend upon the size and nature of the charity and its governing trustees or board, but more significantly depends upon whether principles of good internal governance are in place. ${ }^{136}$ In common with issues around employee disputes, this is not always the case. Potential solutions include time-limited appointments to the board and improvement in guidance for board members. ${ }^{137}$ In the absence of such controls and protocols, the charity may not be working in the best interests of its users and this could contribute to internal disputes and the staffing issues as discussed above.

132 This is particularly true where the practice relates to issues of employment law - see Morris, Disputes (n. 91 above).

133 Under the Supporting People funding initiative, mentally disordered individuals, who have been detained under the Mental Health Act 1983 and discharged with after-care services under s. 117(2), will no longer be funded for housing services, as was the position in the past. Existing charities who have continued to try and house this group without additional sources of funding have run into severe difficulties - The Report, p. 51.

134 This is described as the "founder syndrome" - see B O'Hagan, "Giant step for small charities" (2002) Third Sector Trustee, June.

135 Morris, Disputes (n. 91 above).

136 The charity sector produces a magazine on issues of charity governance, called Governance, details of which can be found at: www.charitygovernance.co.uk/home/8.

137 See, e.g. D. Dalton, “The recruitment and retention of trustees: a perspective from the voluntary sector", in Morris and Warburton, Charities, Governance and the Law (n. 100 above), ch. 3. 
The sector is alive to concerns over governance, which are more far-reaching than the isolated example highlighted here. ${ }^{138}$ One tangible effort to improve standards has been the adoption of a voluntary code of practice on governance, ${ }^{139}$ produced by the Governance Hub, which sets out best practice for trustees based on seven guiding principles. ${ }^{140}$ While compliance with the code is not mandatory, organisations that do so can evidence this in annual reports to the Charity Commission. This provides, in essence, a "kite-marking" system, but as yet there are no compelling statistics as to the current take-up rate of the code, or more particularly how many housing charities have adopted it. Indeed, adherence to the code provides no guarantee of avoiding governance issues and such disputes are still a daily feature of the charity landscape.

\section{Funding and investment}

Even where a charity is true to its values, and not the personalities of its governing body, and keeping a weather eye on peripheral or subordinate issues in service provision, there is a danger of institutional drift. Values change, and at an organisational level, this can be driven by a plethora of external factors. Many charities have merged or refocused their objects to meet different needs arising from changes in funding. ${ }^{141}$ Whether this alteration has been approved through the mechanisms of charity law, which requires the approval of the Charity Commission to the change of objects, is questionable, and the necessary paperwork or management approval may be absent. In such a case, it is difficult to support a contention that a choice to change the values of the organisation has actually been made; rather, it seems as if the charity has drifted towards a new set of values.

Funding can have a pernicious influence on the ability of charities to carry out functions, either through dictating new avenues of service by providing money to support them or by compromising the ability of charities to carry out activities by reducing the levels of funding available. ${ }^{142}$ Long-term planning of service delivery is severely restricted, owing to the fragility of funding streams and the constant pressure on charities to adapt services and locate new financial support to continue. For example, variable and short-term funding which is typically restricted to yearly distribution reduces an organisation's ability to engage in longer-term planning; payment for the provision of services is frequently made in arrears requiring the organisation to establish means to fund an initial service start-up; frequently, full cost recovery is avoided so that the charity finds itself out of pocket when the funder fails to meet all the costs which relate to service provision; and funders have tended to overlook the wider benefits, such as social cohesion and the growth of community spirit, that accrue from using charities and/or third-sector organisations in service provision and, as a result, do not place a monetary value upon these wider benefits.

The change in government practice within the sector from giving block grants to charities to making them tender for bids, the "contract culture", has had a profound effect

138 For a good discussion of the issues, see the collection of papers in Morris and Warburton, Charities, Governance and the Law (n. 100 above).

139 Good Governance: A code for the voluntary and community sector (July 2005). A free copy of the code (and a summary) can be obtained from the Governance Hub website at: www.governancehub.org.uk.

140 Broadly, these principles, which include measures such as managing risk, ensuring equality and diversity, strategic direction and open communication, are designed to offer a complete governing ethos for organisations which choose to adopt the code.

141 One charity was formed as an offshoot of an existing organisation to tackle the lack of specialist mental health service provision offered by housing associations, following their focus on general provision - The Report, p. 26.

142 Ibid., pp. 51-3. 
on the way charities conduct business. Garton observes that the cumulative effect of charities' involvement with the contract culture has been that funders enjoy too much influence in the operation of charities, and co-operation in the charitable sector is weakened by charities competing with each other. ${ }^{143}$

Funding is a constant problem for housing charities both in terms of obtaining initial capital in order to initiate housing projects and finding ongoing funding for the management of housing provision. ${ }^{144}$ More specifically for the vulnerable, evidence suggests that Supporting People funding, which is the current Government's solution to funding of support services, "is about the charitable housing body performing according to a given set of criteria rather than trying to work with the individuals who come to them with a recognised need". 145 The autonomy of charities in decision making is not aided by what charities perceive as their relatively weak bargaining position in securing funding, even though there is evidence to suggest that this is more perception than reality. ${ }^{146}$ Given such concerns, can it really be said that charities are value driven alone, or are they in the best position to deal with funding issues?

There is considerable cause for concern. Research commissioned by the charity regulator, the Charity Commission, into public service delivery by charities found that many charities are increasingly dependent on state funding to carry out their services; for example, just over one-third of the over 4000 charities surveyed obtained 80 per cent or more of their income from this source. ${ }^{147}$ More importantly, only 12 per cent reported that they obtained full cost recovery, with over 43 per cent indicating they do not obtain full cost recovery for any service they deliver. ${ }^{148}$ The survey also concluded that this dependency and underfunding could combine to undermine the ethos and autonomy of organisations, as well as destabilising the charities themselves. ${ }^{149}$

One source of funding which charities enjoy above other organisations is, of course, income from voluntary donations or fundraising; voluntary income constitutes about 55 per cent of the total income of the top 500 charities. ${ }^{150}$ Whether fundraising is a feature of a housing charity will be dependent upon the characteristics of the particular charity, as, for many charities, the major source of income will be local authority funding or by bid (for sources such as Supporting People income), but fundraising will still remain important. Public donations set charities apart from other third-sector organisations, and highlight the essential nature of public trust in charities, for without these donations, many charities would simply struggle to survive.

\section{THE PUBLIC PERCEPTION OF TRUST IN CHARITIES}

It has already been observed that public trust in charities underpins charitable activity across the sector. This is significant as without trust public confidence in charities and public

143 J. Garton, "Charities and the state" (2000) 14 Trust Law International 93. For an exploration of these issues in practice, see D Morris, Charities and the Contract Culture: Partners or contractors? Law and practice in conflict (Liverpool: Charities Law Unit, 1999).

144 See, generally, P Malpass and H Aughton, Housing Finance: A basic guide (London: Shelter, 1999).

145 The Report, p. 52.

146 See Blackmore et al., Reform of Public Services (n. 68 above), pp. 10-14.

147 Charity Commission, Stand and Deliver (n. 13 above), p. 6.

148 Ibid., p. 10.

149 Ibid., p. 23.

150 C Pharoah and S Street, Dimensions 2000: An update on CAF's top 500 fundraising charities (Tonbridge: Charities Aid Foundation, 2001). 
donations to them will decrease. It remains to be seen whether housing charities do, in fact, enjoy high levels of public trust or whether this too differs in practice on the ground.

\section{The importance of public trust}

Charities and its regulators are, as already discussed, aware of the need to protect the charity "brand". Nevertheless, it has been recognised that for individual charities, lack of performance indicators, such as charity league tables, means that regulation of charities and reporting mechanisms must be clear, robust and easily accessible if public confidence is to be maintained and means of improvement are to be provided. ${ }^{151}$ Similarly, organisational and public perceptions of charities are also coloured by the fact that there is too much replication in the charity sector: 'The public thinks that there are too many charities; businesses think that there are too many charities; funders think that there are too many charities.' ${ }^{\text {152 }}$

At organisation level, the issue of branding to ensure a distinctive character and the creation of a positive image in the public mind is becoming increasingly important, mirroring practice in the commercial sector. Nevertheless, charities must be aware of the potential pitfalls behind branding, for example, re-branding may carry with it a negative public perception that money is being wasted on internal charity administration rather than going towards fulfilling its objects. ${ }^{153}$

Housing charities dealing with the vulnerable face an additional problem, especially where they provide or supplement services alongside other providers, rather than acting as sole providers. This relates to the public perception of whether such charities are viewed as independent of government. ${ }^{154}$ The public's opinion of whether a given charity is independent is also essential. Charities must not simply be independent, but must be seen to be independent, as public concern is motivated by the fact that public monies are given to charities either directly or in the form of tax relief. This situation explains why the private sector is never accused of not being independent, no matter how closely it works with government. ${ }^{155}$ It is here that public perception of charities is demonstrated to be "fickle", 156 as the

public ... appear to have "blurred vision" when it comes to VCOs [Voluntary and Community Organisations] . . . high expectations exist alongside a perception that "proper" charities are and should be amateur ... [and] . . . the freedom and flexibility of VCOs to determine how best to meet their aims also means that the sector is largely unregulated. ${ }^{157}$

That this perception exists, against clear evidence of regulation in the sector, suggests at best that charities and interest groups must be more proactive in championing the sector, and at worst that such ingrained beliefs will be extremely difficult to surmount.

Poor perceptions of charities are not helped by the reality of clear weaknesses in the current regulatory and accountability frameworks. One such weakness is the lack of

151 The Charity Act 2006, which received the Royal Assent on 8 November 2006, introduces a number of amendments to existing charity law - see the Charity Commission website for a detailed summary of the impact and history of the Act at: www.charity-commission.gov.uk/spr/charbill.asp.

152 W Barr and J Warburton "Charity mergers - property problems" (2002) 66 Conv 531.

153 See, e.g. P Hankinson and C Rochester, "The face and voice of volunteering: a suitable case for branding?" (2005) 10 International Journal of Nonprofit and Voluntary Sector Marketing 93.

154 A Blackmore, Standing Apart, Working Together: A study of the myths and realities of voluntary and community sector independence (London: NCVO, 2004), p. 17.

155 Blackmore, Standing Apart (n. 154 above).

156 Ibid., p. 23.

157 NCVO, "Blurred vision" (n. 64 above), p. 25. 
information sharing between regulators, which means that the same information is frequently duplicated at the expense of charities. Following recognition that the current mechanisms for accountability are weak, ${ }^{158}$ the Charity Commission, as principle regulator, has sought to make improvements in regulatory practice, including the adoption of the five principles - recommended by the Better Regulation Task Force - that their work will be transparent, accountable, consistent, proportionate and targeted. ${ }^{159}$ There is, however, deep disagreement within the charity sector as to what appropriate regulation should be and what the role of the Charity Commission is within that framework. The Charity Commission's vision of itself as a modern regulator ${ }^{160}$ has drawn considerable criticism from the National Council for Voluntary Organisations (NCVO), one of the leading voices of the voluntary sector. The major concern is that "in carrying out these roles the commission will become too closely associated with the sector, potentially undermining public confidence in its role and in charity as an independently regulated activity". ${ }^{161}$ While it is doubtless true that the $\mathrm{NCVO}$ as an organisation has some self-interest in keeping the commission out of a lobbying role for charities, the underlying conflict between the two proposed roles and the likely public reaction to it are difficult to dispute.

Of even greater concern is the suggestion that close working relationships between charities and government will lead to public confusion as to the identity of charity trustees and a loss of public confidence in charities. The net result would be that " $t]$ he spirit of the gift will be weakened by the prospect that any gift is a gift to the Chancellor of the Exchequer". ${ }^{162}$ The clear impact of this could be that donations to charity might decline the public would not want to feel they are paying twice for the same service. If the public perception of charities is already misguided, even though there is a clear recognition that they are a necessary part of society and do a valuable job, how much more skewed will the image become when charities and the state are working together under the same service provision umbrella?

\section{Theory in practice: the modern decline in charitable giving}

In the wider charitable context, the increasingly negative public perception of the value of charities is amply demonstrated by a modern decline in charitable giving. It is speculated that a third of adults in 2005 were "not in the habit of giving to charity and a great deal of giving potential lays dormant much of the time". ${ }^{63}$ Many of the factors that lie behind this have been identified, ${ }^{164}$ including negative attitudes towards the helping of others and towards charitable organisations as a result of apparently intrusive fundraising methods, the use of for-profit enterprises in the collection of donations and the perceived (un)trustworthiness of the charitable organisation in the way in which it carries out it's functions. This recognition has not arrested the decline.

\footnotetext{
158 The Charity Act 2006 introduced a new Charity Tribunal, which may help regulation.

159 Charity Commission, Charity Working at the Heart of Society - The way forward 2005-2008 (London: Charity Commission, 2005).

160 Ibid.

161 See B Pratten, Response to the Charity Commission Strategy, "Charity Working at the Heart of Society - The Way Forward 2005-2008” (London: NCVO, 2005).

162 C MacLennan, "Local government and charities" (2005) PCB 241, 247.

163 S Hibbert and T Farsides, "Charitable giving and donor motivation", ESRC Seminar Series: Mapping the public policy landscape (London: ESRC/NCVO, 2005), p. 2.

164 A Sargeant and E Jay, "Reasons for lapse: the case of face-to-face donors" (2004) 9 International Journal of Nonprofit and Voluntary Sector Marketing 171.
} 
According to the Henley Centre, confidence in voluntary and charitable organisations has vastly reduced since the mid-1980s. ${ }^{165}$ "In 1996 the number of people having 'a great deal' or 'quite a lot' of confidence in charities stood at 33\%"; better than the church (25 per cent), the Government (11 per cent) but worse than the NHS (40 per cent), banks (46 per cent) and the police (58 per cent). ${ }^{166}$ In 2000 , the NCVO "expected that public trust in voluntary organisations' motives [would] decline" and Hibbert's recent research has confirmed this. ${ }^{167}$ This means that there is a significant tranche of British society unwilling or inactive within the charitable process, which at least raises some interesting questions as to the perceived relevance and value that is attached to the activities of charities in the provision of services and the meeting of unsupported social needs.

Whether this translates directly to housing charities for the vulnerable, as many derive their operating income from other sources, it does at least demonstrate that there are some major concerns within the sector about trust and confidence. Indeed, research into public service delivery by charities, of which housing forms a part, suggests that where funding instead comes from the state, there are similar concerns over independence, autonomy and public trust. 168 Taken with the factors identified above, this suggests that not all charities may enjoy the level of public support that is commonly assumed.

\section{Looking forward}

The foregoing analysis has suggested that, while charities do make an important and worthwhile contribution to service delivery for the mentally vulnerable, there are a number of factors and processes which may dilute these benefits, or reduce their significance. Similarly, some of the issues explored suggest that charities' infrastructure and resources are stretched. It remains to consider the position in the future, in which an increasing role for charities in direct public service provision is envisaged.

The major new housing policy initiative is to involve charities and the wider third sector directly in discharging public service functions by focusing on the quality of provision, rather than the sector which provides it. ${ }^{169}$ This approach focuses on the state acting as a provision enabler, and supplying housing through partnership and joint working. What is new is that charities will be expected to provide public services directly, rather than supplement them as in the past. The decision of the Charity Commission, that charities may use funds to pay for services that a public body ${ }^{170}$ provides, sets the legal platform to allow charities to become major providers of public services. In allowing a departure from their traditional role of innovating service provision or filling the gaps left in public provision, this marks an important change from past practice. The question which needs to be explored is whether they should be so involved and what this means in relation to the future of provision for the vulnerable.

This single most important issue, it is suggested, is whether charities' infrastructure can meet the increased demands of public service provision and whether structural fragmentation is an inevitable result. It is also clear that several associated difficulties exist such as, whether there are effective funding regimes, the question of multi-agency working

165 Henley Centre, Planning for Social Change 1996/97 (London: Henley Centre, 1997).

166 Ibid., p. 7.

167 Hibbert and Farsides, Charitable Giving (n. 163 above).

168 Charity Commission, Stand and Deliver (n. 13 above), para. 2.1.

169 See, e.g. Home Office, Working with the Third Sector (London: TSO, 2005).

170 See Charity Commission, Decisions of the Charity Commission For England and Wales, Applications for Registration (i) Trafford Community Leisure Trust and (ii) Wigan Leisure and Culture Trust, April 2004. Originally, charities could only supplement what the public authority provided. 
and whether reliance on a multi-tier system of service provision ultimately results in a fragmented system which is of benefit to none. It is clear that should reliance upon charities to provide public services continue, the nature and shape of the charitable sector will change significantly. The Charity Commission acknowledged that particularly the mediumsized charities would struggle the most to compete for sustainable public funding, while small charities will continue to offer supplementary services and large charities will be the dominant public service providers in the sector. It is anticipated that not all charities harnessed to provide public services will have the structural capacity or resources to meet the demands of public service delivery and, for these charities, very difficult times are expected ahead. The Government has acknowledged the potential shortfall in charitable infrastructure and has made commitments to bolster this in the future. However, the Charity Commission observes that "the achievement of government targets to increase the level of charities' participation in public service delivery will depend heavily on the successful implementation of these commitments". ${ }^{171}$ Whether such targets will be met, is, of course, speculative, and is not guaranteed.

Of equal significance, the increased role of the third sector in housing provision in partnership with government also has the potential to strain the independence of charitable organisations beyond recognisable limits. Charity Commission research has found that the level of involvement charities have in public service delivery is influencing the public's perception of the independence and governance of charities. When charities carry out activities or provide services primarily for funding purposes, or where a public authority exercises significant control over decision-making, these situations can suggest that charities are no longer directed by their objects or are free from outside influences. The smallest hint of this can result in the key benefit of independence being immediately lost. ${ }^{172}$

It is difficult, in this context, not to see current policy trends in a negative light; rather than growing state provision to meet what charities have been doing better, it is delegating provision to charities as the current champion of such services, without thinking through the implications. This is, arguably, strategic delegation, not planning. There is currently a necessary informal partnership between state provision and charities, even if it does not work as well as one might like. Extending this beyond this partnership to make charities a major arm of service provision, rather than an important and necessary supplementary service, seeks to destroy that balance. Charity Commission evidence suggests this is so, and calls for greater control and thinking on this issue. ${ }^{173}$

On the other side of the housing equation, the number of people with recognised mental illness and vulnerabilities is increasing. ${ }^{174}$ It does not require a leap of reasoning to suggest that the housing needs are also going to grow, particularly against a background of a paucity of suitable housing stock. ${ }^{175}$

What this article has sought to demonstrate is that, while such problems cannot be ignored, increasing charity involvement in this area is not a replacement for much needed strategic thinking to ascertain the exact nature of the problem and any appropriate responses that might be needed. Policy makers need to stand back and recognise that problems of this kind cannot be overcome by making small, peripheral changes to

171 Charity Commission, Stand and Deliver (n. 13 above), p. 22.

172 Ibid., p. 20.

173 Ibid., p. 23.

174 At some point during their lifetime, 1 in 4 adults are expected to suffer a mental disorder. In 2004, it was established that 1 in 10 children in Great Britain have a mental disorder; a worrying statistic for the future (Department of Health).

175 The Report, p. 32. See also Glover-Thomas and Barr, "Housing an individual" (n. 20 above). 
individual elements. Indeed, in particular, such change may damage the whole sector whose strengths the state seeks to yoke.

\section{Concluding thoughts}

It is difficult to know what possible system could be designed to replace the fragmented tapestry of provision which currently exists for mentally vulnerable individuals and into which charities provide so much of the support. Indeed, it may be that there is no alternative to the current system, and that, while imperfect, the existence of charities and other specialist providers is the key to provision for the most vulnerable in society. This piece has not sought to provide the shape to any overall solution to the needs of the vulnerable in housing. At the very least, further research and energies should be directed to finding better methods of supporting both charities and other providers. Some factors worthy of consideration include methods of improving joint working practices, creating a centralised data repository, establishing a body which deals with the housing needs of the mentally vulnerable alone, and the creation of an advocacy service that aids communication and understanding between users and providers. ${ }^{176}$ Without these there is a very real danger that the quality of provision currently available to the mentally vulnerable will further deteriorate over time. The weaknesses outlined above will only increase and there are limits to what even the best charities can achieve when it is the system itself that is at fault.

176 Some of these suggestions are considered in The Report to help providers improve the current situation, see ch. 5. Obviously, this is a response to inadequacies within current practice rather than an attempt to suggest components of a new system. 